\title{
The Effects of Minimum Bid Increment in Internet Auctions: Evidence from a Field Experiment
}

\author{
Janne Tukiainen \\ HECER and Government Institute for Economic Research VATT
}

Discussion Paper No. 329

May 2011

ISSN 1795-0562

HECER - Helsinki Center of Economic Research, P.O. Box 17 (Arkadiankatu 7), FI-00014 University of Helsinki, FINLAND, Tel +358-9-191-28780, Fax +358-9-191-28781,

E-mail info-hecer@helsinki.fi, Internet www.hecer.fi 


\title{
The Effects of Minimum Bid Increment in Internet Auctions: Evidence from a Field Experiment ${ }^{\star}$
}

\begin{abstract}
I study the role of a minimum bid increment (MBI) in Internet auctions. I estimate the causal effect of $\mathrm{MBI}$ on prices and entry using field experiment data. I sell two sets of identical gift cards using three different MBI levels within set. I find that the revenue maximising level for $\mathrm{MBI}$ seems to be larger than zero and that the eBay-level seems to be close to optimal. Moreover, MBI limits entry as expected. These effects are both statistically significant and economically relevant. Furthermore, I conduct a structural econometric test using my experimental data that distinguishes between different theoretical explanations for the revenue result. Test results suggest that due to MBI, Internet auctions are not second price auctions, unlike previously assumed.
\end{abstract}

JEL Classification: C52, C72, C93, D44, L81

Keywords: field experiment, Internet auctions, minimum bid increment, model selection, revenue.

Janne Tukiainen

HECER

P.O. Box 17 (Arkadiankatu 7)

FI-00014 University of Helsinki

FINLAND

e-mail: janne.tukiainen@helsinki.fi

* I thank Estelle Cantillon, Phil Haile, Brent Hickman, Ari Hyytinen, Klaus Kultti, Laurent Lamy, Emmi Martikainen, Harry Paarsch, Matti Sarvimäki, Otto Toivanen, Alexander White and Hanna Willman-livarinen for comments, Niklas Jahnsson for excellent research assistance and Toni Ruuska at Huuto.net for industry expertise. Conference participants at EARIE-10, FEAAM-10 and Toulouse-11, and seminar participants at HECER, London School of Economics (LSE) and Paris School of Economics provided useful discussions. I am grateful to the Yrjö Jahnsson Foundation (YJF) for funding this particular experiment and to the Emil Aaltonen Foundation for generous funding in general. I thank STICERD at the LSE for hospitality and Jenny and Antti Wihuri Foundation and YJF for funding this visit. 


\section{Introduction}

Online auctions and electronic procurement account for a large and increasing share of $\mathrm{C} 2 \mathrm{C}$ trading, retail trade (B2C) and B2B trading. In this study, I argue that in such online or Internet auctions, a minimum bid increment (MBI), which refers to the minimum amount that a new bid must exceed the current price for it to be accepted, is potentially an economically important but empirically overlooked feature of the auction design. The received theory predicts that MBI may be an important determinant of Internet auction revenue and that the revenue maximizing MBI may be larger than zero. One of the two main contributions of this study is that I use a novel field experiment to show that both of these theoretical predictions are supported by data. I document, in particular, that increasing MBI increases the seller revenue up to a point but limits entry.

MBI is a close relative of a bid increment grid used sometimes in standard auctions, but there are important differences which may result in opposite policy recommendations. In most standard auctions, the optimal increment is zero, but due to the particular features of online auctions, the optimal level of MBI may be larger than zero. In online auctions, the MBI affects not only whether a new bid is accepted, but also how the price is determined. Most importantly, the larger the MBI the larger the likelihood that the pricing rule is based on the first price instead of the second price mechanism. Because MBI adjusts the probability that the pricing rule in a given auction is either a second price or a first price rule, it could have significant impact on the revenue in situations where the revenue equivalence does not hold. Moreover, the revenue maximizing MBI may well be larger than zero, unlike in standard auctions.

Due to having implications on the pricing rule, MBI should be also an important determinant of bidder behavior. The other main contribution of this paper is that I show by applying a structural econometric test on my field experiment data that bidders do indeed account for MBI in their bidding strategies. The main implication of this test is that Internet auctions should not be modeled as second price auctions as most of the existing literature does. This test contributes to the recent discussion on what is the correct framework for the analysis of Internet auctions. Zeithammer and Adams (2010) provide novel model validation tests and empirical evidence that the second price sealed bid assumption that is prevalent in the empirical literature (e.g. Bajari and Hortacsu 2003 and Song 2004) is not the correct one in eBay auctions. They show evidence that while some bidders may submit sealed bids, a significant amount of bidders conduct a variation of ascending auction behavior called incremental bidding, where the current price is raised by one MBI at a time up to a valuation. This is a more fundamental distinction than just whether these are sealed bid or standard ascending auctions, because with incremental bidding, the top two bids in these auctions no longer reflect the true bidder valuations. Hortacsu and Nielsen (2010) contribute to this discussion by 
providing a commentary on Zeithammer and Adams (2010). They argue for the importance of incorporating richer models to structural analysis of Online auctions, but remain optimistics that it is possible. Although Zeithammer and Adams (2010) utilize information on MBI in their tests, they overlook the implications of MBI on entry and strategic behavior. My contributions is to show some empirical evidence that even if some bidders submit sealed bids, they are not second price bids because MBI induces bid shading behavior similar to first price auctions. This is a more fundamental concern than incremental bidders for the empirical analysis of Internet auctions, because it may well be impossible for the bidders to formulate optimal first price bidding strategies, because the number of potential bidders is unknown to everyone, and unlike in second price auctions or incremental bidding, first price auction strategies are a function of the number of potential bidders.

In some Internet auction sites, like the Finnish site Huuto.net, it is possible for the seller to choose MBI freely as one parameter of the auction design. However, most Internet auction sites follow eBay and do not allow the seller to choose MBI but rather force an increment schedule that is a step function of the current price. I utilize the properties of Huuto.net to set up a novel field experiment to study the causal effect of MBI on the seller revenue, the bidder participation and bidding strategies. In my field experiment, I sell 72 Stockmann gift cards each valued at 15 euro at three different MBI levels and also 72 Stockmann gift each cards valued at 50 euro at three different MBI levels. Stockmann is the largest department store chain in Finland. I use increments of 1 cent, 33 cent and 50 cent for the 15 euro cards and increments of 1 cent, 66 cent, 100 cent for the 50 euro cards. 1 cent is the smallest possible level, and 33 cent and 66 cent correspond to what eBay would have set at that particular price range.

In most existing studies on Internet auctions (see for example a survey by Ockenfels et al. 2006), MBI has been assumed to be too small to have any impact on bidder strategies or auction outcomes. However, there has been some work in management science and computer science that argue for the importance of MBI in Internet auctions. Bapna et al. (2003) provide theoretical results concerning B2C online auctions. In their model, it turns out that MBI is the most important parameter that the seller can choose. Also Rogers et al. (2007) analyze MBI from a theoretical perspective. According to their model and simulations, the seller can maximize revenue by setting reservation price to zero and MBI to an optimal level that is larger than zero. According to these studies, MBI seems to be even more important mechanism parameter than setting the reservation price optimally, which has been at the center of auction research ever since Myerson's (1981) seminal contribution. However, these results hinge on behavioral assumptions on the bidder behavior. The result in Rogers et al. (2007) for example requires that all bidders submit a single truthful bid. Hickman (2010) provides in a simplified setting the only existing analysis on how MBI affects strategic bidding in Internet auctions. He shows that MBI is a very important and unique feature of electronic auctions and it 
makes these auctions a hybrid between second and first price auctions. However, his otherwise insightful analysis does not address the relationship between MBI and the seller revenue.

Despite the scarcity of theoretical literature, relative to the importance of this question, empirical contributions are even more scarce. Bapna et al. (2003) provide the only other empirical attempt to study the association between MBI and the seller revenue. They use observational data from B2C online auctions. However, Bapna et al. (2003) do not address the potential problems regarding unobserved heterogeneity in any way. Moreover, their sampling procedure introduces a selection bias since they exclude auctions with low participation from the data. Because low participation may be caused by high MBI, this selection may result in overestimating the effect of MBI on the revenue. Therefore, their results should be taken merely as descriptive, but as such these results validate their theoretical argument that MBI is the most important parameter in these auctions. To my knowledge, my study is the first empirical analysis that estimates the causal effects of MBI on auction revenue and entry. Moreover, my experiment allows me to analyze whether eBay uses an optimal increment function. The gap in both the theoretical and empirical literature concerning the analysis of MBI could be due to the seller not being able to set the MBI in the large Internet auction sites like eBay. Another explanation is that MBI may be regarded only as a minor detail of these auctions.

Despite the lack of studies concerning MBI in particular, Internet auction sites like eBay have proven to be a rich source of both observational and experimental data for auction researchers, for example wanting to test theory. Moreover, they have also been the main objects of numerous studies, both theoretical and empirical. Bajari and Hortacsu (2004) and Ockenfels et al. (2006) survey the literature on Internet auctions. In a typical Internet auction, the auctioneer can make several choices concerning how to sell the object, of which all have been extensively studied with the exception of MBI. These choices all have implications on the expected revenue. First, the seller can set a public reservation price. Reiley (2006) finds in a field experiment that the buyers in his data behave as symmetric risk-neutral bidders with independent private values would in an equilibrium and therefore the seller should set a non-zero reservation price. Second, it is possible to also set a secret reservation price. Katkar and Reiley (2006) compare the use of public and secret reserve prices and find that making the reserve price secret makes the sellers worse off. Third, the seller can allow a buy-now option. There exists many studies concerning the buy-now effects, both theoretical and empirical, including a field experiment by Standifird et al. (2005) but they do not provide a clear answer on when the seller should allow buy-now and at what level. Furthermore, a wide variety of marketing options are available that the site sells to the auctioneer (Canals-Cerda 2006). There are also different ways to disclose information about the object (Andrews and Benzing 2007) and sellers have also the possibility to use an intermediary seller to increase reputation (Resnick et al. 2006). Furthermore, the auction sites differ to some extend in the auction mechanism that they use. For example, the stopping rule can be strict or 
soft, which has implications on the equilibrium behavior (Ockenfels and Roth 2006). It should ne noted that some studies (e.g. Ockenfels and Roth 2006) do account for MBI in their models, but it is not the object of interest.

The use of online auctions and e-commerce has been growing rapidly during the last decade and continues to do so. Currently, a massive amount of transactions are conducted via the Internet and a market can be found for most imaginable items ranging from cloth diapers to start-up companies. For example, the largest online auction site eBay (company's all sites) had a gross merchandize volume of $\$ 60$ billion in 2007. The sheer volume of transactions conducted in the online auctions makes it very important to understand all the details of these auction mechanisms, because even small deviations from an optimal auction mechanism may cause significant aggregate losses for the seller side of the market.

It is likely that an increasing share of public procurement will also be conducted electronically in the future. For example, the new European public procurement directives (2004/17/EC and 2004/18/EC) make it clear that procuring entities can require suppliers to use electronic means (Arrowsmith 2006) and the majority of the member states have declared their intention to adopt eAuction systems (Renda and Schrefler 2006). In a public procurement setting, the social planner prefers the auctioneer's revenue over the bidders', because a public auctioneer needs to collect costly and distortionary taxes to pay the winning bidder. Therefore, it is also very important from the social planner's perspective to understand how the auctioneer can maximize its profits in the Internet auctions.

In my experiment, I find that using the eBay increments increase the seller revenue compared to using the 1 cent MBI. This result is statistically significant at $5 \%$ level. The eBay level brings the highest revenue but the difference is not statistically significant from the higher 50 cent or 100 cent MBI levels. The number of participating bidders seems to decrease the higher the MBI level is. These results imply that eBay has been able to set its MBI schedule close to optimal. However, there are some differences in the auction mechanism used by Huuto.net and eBay that limit the external validity of my Huuto.net results when applied to eBay.

Besides showing that MBI has statistically significant effects on revenue and entry, the experiment allows for different ways to quantify the economic importance of the revenue effect. Using the eBay increments increase the seller revenue compared with using the 1 cent MBI on average by $0.68 \%$ of the nominal value or by $0.77 \%$ of the average selling price. When aggregating over all the transactions conducted in eBay, even this small percentage would have amounted to about 460 million dollars in 2007. This is an estimate of the increase in trade volume that resulted from eBay using their current levels instead of a contrafactual 1 cent MBI for all. A better measure of the revenue gains is the difference the MBI levels make on the costs of running this experiment as measured by the nominal value minus the selling price. Using the eBay level instead of the 1 cent MBI, decreases the costs of this experiment on average by $5,7 \%$ per unit of observation. 
In summary, my experiment reveals that MBI is a relevant determinant of the online auction revenues, both in statistical and economic terms. Its estimated effect on a measure similar to turnover is just below $1 \%$ and on a measure similar to net profits just below $6 \%$.

My field experiment data also allows me to test for truthful bidding. If bidders behave as if this was a second price auction, they would submit their true valuations as bids. Assuming truthful bidding, I can calculate valuations based on the winning bids and the pricing rule that was used. I then test whether the valuation functions generated by auctions with different MBI are the same. I reject the null of truthful bidding, and find that auctions with higher MBI generate valuation functions that have more weight on lower valuations. Since MBI does not affect valuations as such, this result is consistent with bid shading that increases with MBI, exactly as Hickman's (2010) model suggests.

In Section 2, I describe how a typical Internet auction works and discuss some Internet auction specific theory to frame the experiment. I also discuss what questions the theoretical literature should target in my opinion. In Section 3, I present and discuss how I set up the field experiment and in Section 4 I analyze the results of the experiment. I also propose and conduct a structural test to distinguish between different theoretical explanations for my results in Section 5. Section 6 concludes.

\section{The institutional set up and some theory}

In this section, I discuss some of the properties of eBay, the largest Internet auction site and Huuto.net, the site where I conduct the experiment. Most Internet auction sites work in almost exactly the same way as eBay. eBay auction is a variation of an ascending auction with a minimum bid increment, fixed closing time and a proxy bidding system. In eBay, the bidders are forced to use the proxy system, but they can circumvent this by submitting only bids equal to the current price plus MBI. This is called incremental bidding. Both eBay and Huuto.net sites advice the buyers to submit only their true valuation once and let the proxy do the rest. This is called proxy bidding. Although from the surface these auctions look like ascending auctions, it is generally thought that the equilibrium in Internet auctions is equivalent to the equilibrium in sealed bid second price auctions, and not that in ascending auctions (e.g. Bajari and Hortacsu 2003, Song 2004).

From empirical perspective, there is not much difference between the sealed bid second price auction or the ascending auction, because in both of these second price situations the transaction price is the second highest valuation. However, due to the interplay between MBI and the pricing rule, which's effects on equilibrium behavior the previous literature, with exception of Hickman (2010), has overlooked, the second price scenario does not exactly apply in these auctions. Furhermore, Zeithammer and Adams (2010) show 
that MBI together with incremental bidding implies that the first and second bid may be downwards biased from true first and second valuations.

In these auctions, the seller has some control over the auction menchanism. The seller has to set some starting price, which is equivalent to setting a public reservation price. There is also a possibility to set a secret reservation price. In addition to these parameters, the sites sells the sellers a wide variety of marketing options. In Huuto.net, it is also possible to set MBI level. This is not possible in eBay. I discuss the other differences between eBay and Huuto.net in the results Section when I analyze the external validity of my results. Table 1 shows the MBI schedule that is used in eBay. As explained below, I use the eBay level as one of the treatments in my field experiments.

Table 1: MBI schedule in eBay.

\begin{tabular}{|c|c|}
\hline Current Price & Bid Increment \\
\hline$\$ 0.01-\$ 0.99$ & $\$ 0.05$ \\
$\$ 1.00-\$ 4.99$ & $\$ 0.25$ \\
$\$ 5.00-\$ 24.99$ & $\$ 0.50$ \\
$\$ 25.00-\$ 99.99$ & $\$ 1.00$ \\
$\$ 100.00-\$ 249.99$ & $\$ 2.50$ \\
$\$ 250.00-\$ 499.99$ & $\$ 5.00$ \\
$\$ 500.00-\$ 999.99$ & $\$ 10.00$ \\
$\$ 1000.00-\$ 2499.99$ & $\$ 25.00$ \\
$\$ 2500.00-\$ 4999.99$ & $\$ 50.00$ \\
$\$ 5000.00$ and up & $\$ 100.00$ \\
\hline
\end{tabular}

There is some theoretical work that analyze bid increments in traditional auctions. Chwe (1989) shows that in a first-price sealed-bid auction with no entry and bidding costs, the auctioneer should set the increments as small as possible. Rothkopf and Harstad (1994) show, although with restriction on the number of bidders or the number of possible increment levels and on the distribution of valuations, that English auctions with discrete bid levels generate less expected revenue than auctions with continuous increments. This implies that the auctioneer should always set the increment level to zero to maximize revenue. The main idea of their proof is that although there are special cases where a high increment could result in a higher revenue, the probability of these events is lower than that of those cases where high increment decreases revenue. David et. al (2007) generalize these results for English auctions and come to same the conclusions. However, they make a point that if submitting a bid or time spent in auction is costly, the revenue gains 
from small increments should be weighted against these costs. These results imply, that if we assume that Internet auctions operate as standard ascending auctions, increasing MBI should decrease seller revenue. Since my results indicate the opposite, we can conclude that a standard ascending auction is not probably the correct model for bidding behavior in Internet auctions.

Despite the theoretical results that support the use of low MBI, eBay uses relatively large MBI's, especially for low value objects, and in Huuto.net, the sellers typically set MBI higher than the smallest possible level. In Figure 1, I show the empirical density of MBI used in some Huuto.net auctions. MBI of 0.5, 1 and 2 euro are most common and very small MBI's are rare. One possible reason for this behavior is that if the bidding process in Internet auctions is the same as in a sealed-bid second-price auction, instead that of an English auction, and since the winner pays the second highest bid plus MBI, then the expected revenue is equal to the second highest bidder's valuation plus MBI (e.g. Bapna 2003). However, this holds only if there is no endogenous entry and bidders submit true valuations. Next, I present another potential explanation for this behavior that is related to how the Internet auction protocol differs from a traditional auction. 
Figure 1. Density functions of MBI's by starting value groups in Huuto.net for packages of used children's clothing in auctions that started between 28.12.2010 and 3.1.2011.

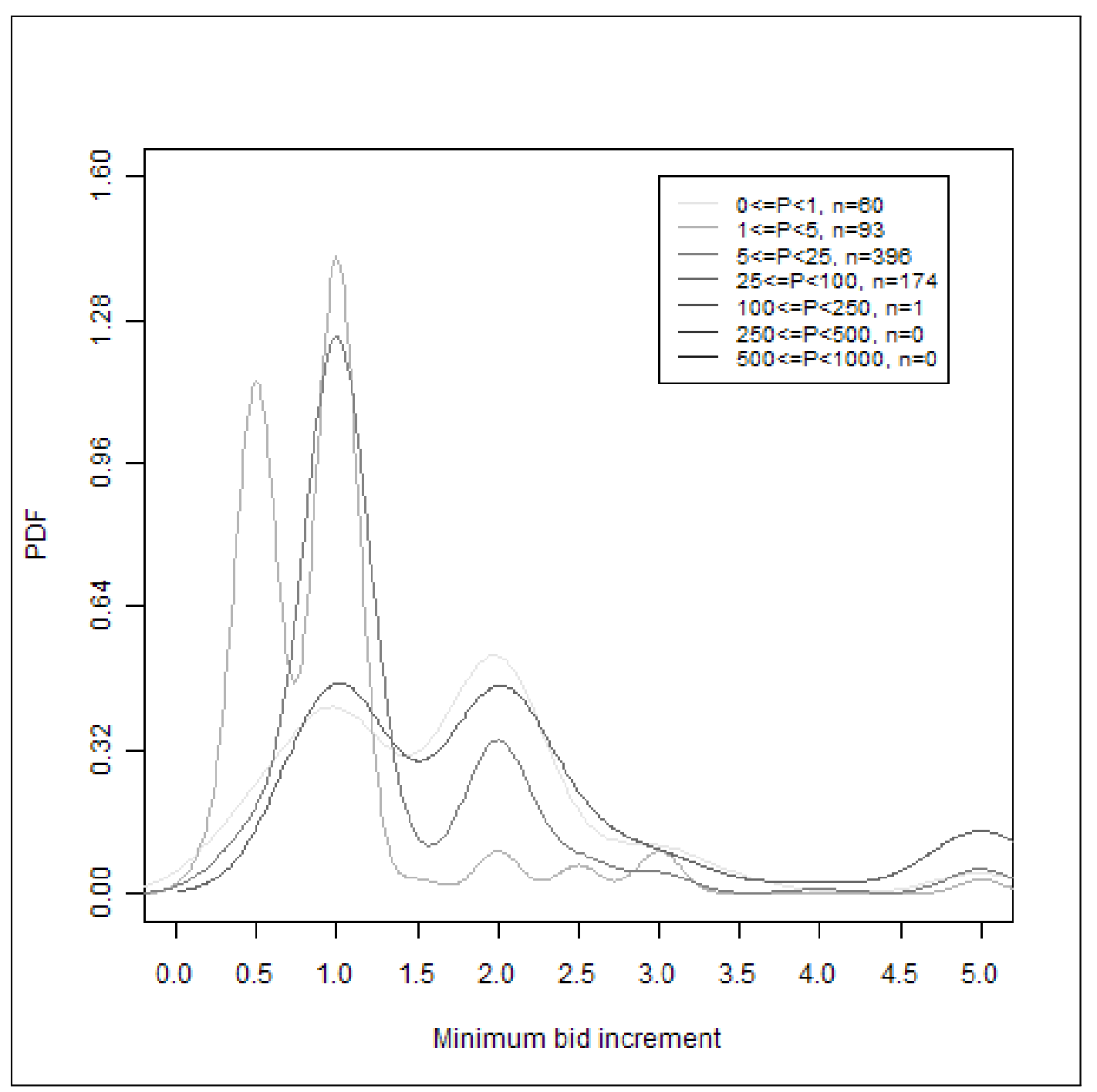

\subsection{MBI and the proxy bidding system}

Rogers et al. (2007) study the joint effect of proxy bidding system and minimum bid increments on revenue. They motivate their work by stating that they try to solve the contradiction between the usual assumptions that eBay behaves as a second price auction whereby the expected revenue is equal to the second highest 
bidder's valuation plus MBI (e.g. Bapna 2003 and Ockenfels and Roth $2006^{1}$ ) and the results by David et al. (2007) and Rothkopf and Harstad (1994) who both argue that these auctions generate less revenue than the second highest valuation because of the discrete bid grid. Rogers et al. (2007) provide a model of eBay auction protocol with two bidders that have private values. This model allows a detailed analysis of how the proxy bidding system and minimum bid increment interact and affect the properties of these auctions. They simulate the results for more than two bidders.

The main finding in Rogers et al. (2007) is that the expected revenue depends on the MBI and this effect is dependent on how the bidders play the game. If all bidders submit their true valuations to the proxy, the expected revenue is higher than the second highest valuation but by an amount less than the MBI. In this case, there is an optimal value for the MBI that is larger than zero. The selling price is increasing in the MBI but this effect is limited from above by the effect of MBI on entry. If all the bidders use incremental bidding, the expected revenue is less than the second highest valuation. Therefore, the incremental model advocated by Zeithammer and Adams (2010) cannot explain why sellers in Huuto.net often choose high MBI. To understand how the MBI affect the revenue, we need to understand how the proxy bidding system works. According to the description in the sites, this proxy protocol is very similar in both eBay and Huuto.net, which I confirmed by some experimenting in the Huuto.net.

For the bid to be accepted, it must exceed the current bid (or the reservation price for the first bidder) plus the MBI. This is the minimum amount that the proxy accepts. It is also possible to set any value that is higher than this to the proxy. The value entered does not need to follow the grid imposed by the MBI. According to Rogers et al. (2007), the common belief is that proxy then engages in incremental bidding each time it is overbid up to the amount given to the proxy. However, this is not the case as Rogers et al. (2007) show by providing a pseudo-code for the eBay protocol. What rather happens is that, whenever a new bidder informs his proxy of his valuation, the current bid immediately advances to the minimum of the highest price entered so far and the second highest price plus the MBI. As argued by Rogers et al. (2007), this system gives rise to the optimal value of MBI. This formula (1) for the current price reveals immediately how the expected current price and therefore the expected selling price is strictly increasing in MBI. However, higher the MBI, the higher is the chance that a new arrival is not willing to submit any bid, even if he has the highest valuation, because the current price plus MBI is more likely to be larger than his valuation when MBI is larger. The current price formula (1) also implies that the current price and therefore the selling price need not be restricted to the integer multiplies of the MBI.

(1) $C P_{t}=\min \left(H B_{t}, S H B_{t}+M B I\right)$,

\footnotetext{
${ }^{1}$ Unlike Rogers et al. (2007) imply, these papers do not make claims about the expected revenue, they merely describe that price is determined in this manner, which is a different matter, unless truthful bidding and no endogenous entry is assumed.
} 
where $C P_{t}$ denotes the current price at time $t$ and therefore also the revenue for the auctioneer at time $t=T$, where $T$ denotes the closing time. $H B_{t}$ is the highest submitted in the auction and $S H B_{t}$ the second highest bid at time $t$. Besides deterring entry, a higher MBI level implies that the current price would more often be determined as the highest bid submitted to the proxy. If MBI is zero, abstracting from endogenous and sequential entry, the price is determined as in a second price sealed bid auction. If MBI is very large, then the price is determined as in a first price sealed bid auction. With intermediate levels of MBI, Internet auction is a hybrid between these two auctions formats. Hickman (2010) shows that this imposes behavior similar to the first price sealed bid auctions, where the bidders shade their proxy bids away from the true valuation in equilibrium. Indeed, he shows that in a Bayes-Nash equilibrium of this game, bidders submit bids that are below their valuations by an amount that is increasing in MBI. Therefore, the optimal MBI is lower than what would be implied in Rogers et al. (2007) setting of truthful bidding.

Hickman (2010) simplifies the model by assuming exogenous entry, symmetric risk-neutral bidders and independent private valuations. Each bidder submits only a single bid to the proxy. Highest bidder wins and the winner pays according to equation (1). Hickman (2010) does not analyze the effect on MBI on revenue, but it is clear that in his model the revenue equivalence theorem (Riley and Samuelsson 1981, Myersson 1981) holds. Therefore, increasing the MBI has two opposite effects on expected revenue that exactly cancel out each other. Increasing MBI increases revenue based purely on the expected revenue being an increasing function (1) of MBI, but simultaneously it increases bid shading by the same amount.

Revenue equivalence between different levels of MBI is broken if endogenous entry is introduced. However, since high MBI limits the potential gains by prohibiting the expected entry of even the highest value bidder, it is likely that endogenous entry would only imply that the optimal MBI is zero. The behavioral explanation of truthful bidding, as analyzed by Rogers et al. (2007) may explain observed seller behavior of setting nonzero MBI and the results of my experiment that optimal MBI is not zero. However, due to not taking bid shading into account, Rogers et al. (2007) overstate the potential revenue gains from MBI. Nonetheless, the presence of bid shading does not mean that there may not be an optimal level above zero even in the presence of endogenous entry. Increasing MBI may increase expected seller revenue in such cases where the first price auction revenue is known to dominate the second price auction revenue, because by increasing MBI the seller increases the probability that an Internet auction behaves as a first price auction instead of a second price auction. Maskin and Riley (1984) show that with risk averse bidders, the revenue from first price auctions dominates the revenue from second price auctions, because risk averse bidders try to avoid the risk of not winning the auction by bid shading less than risk neutral bidders. In this case, higher MBI means higher expected revenue. Che and Gale (1998) show that budget constraints impose a similar bid function that risk aversion, therefore providing another case where increasing MBI may increase revenue. By the 
same revenue comparison logic and the results by Milgrom and Weber (1982), we know that with affiliation the optimal MBI is zero, because then second price revenue dominates first price revenue. The effect of bidder asymmetry may go either way (e.g. Krishna 2002). Therefore, the main candidates for revenue gains from higher than zero MBI are risk aversion and truthful bidding.

The simulation approach that Rogers et al. (2007) use for the $n$-bidder case is not a perfect substitute for an explicit solution nor is it satisfactory to abstract away from strategic considerations. Fully characterizing the strategic behavior of bidders in online auctions in relation to the MBI in a setting that incorporates endogenous entry and other realistic features of these auctions would be an important contribution to the literature, but is clearly beyond the scope of this paper. Such a model could allow for a structural empirical analysis of these bidding markets. However, one limitation of structural empirical analysis of Internet auctions is that the number of potential bidders is not known and it could be hard to estimate because it may be very large. Moreover it is not unobservable only to the econometrician but also to the bidders. The auction model should also incorporate this uncertainty. On the contrary to structural modeling, main purpose of this study is to provide reduced form field experimental evidence to show that MBI is indeed an important subject of further research. Moreover, using data generated by an experiment it is possible to construct a structural test at least for the truthful bidding assumption.

\section{The experiment}

I conduct a field experiment to study how MBI affects selling prices. As a secondary objective, I also look at how it affects the number of observed bids and observed bidder identities. In this experiment, I sell Stockmann gift cards. Stockmann is the largest department store chain in Finland. The gift cards are valid in all of Stockmann's seven large department stores in Finland. These seven stores are located in the six largest cities in Finland that together have 1.6 million inhabitants or about $30 \%$ of the entire population. These stores sell millions of different commodities and services. They are also valid in company's subsidiary stores like Seppälä, that sells clothes in 90 different Finnish cities and tows. Seppälä is thus easily accessible by most of the population in Finland. These gift cards were chosen for this experiment mainly because there is a large demand for these products. It is almost like selling money. It is very likely that the potential demand for the last card sold is about the same as for the first card sold. However, this assumption is not necessary for the internal validity of the experiment. It is enough that demand is fairly stable within each card batch that I sell.

Another property that the gift cards in general have, is that bidders have very likely private valuations for 
them, since there is no significant common uncertainty about the value of these objects. Relevant uncertainty is essentially private. For example, the bidders may have different transaction costs, may discount future at different rates, have different use for these cards and may have different perceptions on the trustworthiness of the seller. All this uncertainty is private. This assumption of private values is not necessary for the internal validity of this experiment either. With independent private values, it is just more likely that the experiment would result in revenue gains from increasing MBI than under other information assumptions such as the affiliated values framework.

In the first experiment, I sell a total of 72 identical 15 euro Stockmann gift cards. 24 are sold at 1 cent MBI. This constitutes the control group. There are two treatment groups, the 33 cent MBI (eBay level) and the 50 cent MBI. The second experiment is run in exactly the same way, with the exception that the the cards have now a nominal value of 50 euro, and the MBI levels are now 1 cent, 66 cent (eBay level) and 100 cent. It would be interesting to set one treatment in the experiment to optimal MBI, but unfortunately it is not possible.To be able to calculate the optimal MBI for the objects sold in the experiment, I would need to know many unobservable factors, such as the number of potential bidders and their value distributions, the nature of the entry process and bidder strategies. Not mention that also the relevant theory for this calculus does not exist. Therefore, the most interesting possible set up is to look how the eBay level performs compared with the minimum level and a higher level.

The experiment is conducted with objects that have both the reservation price (starting price plus MBI) and the maximum selling price (the nominal value of the card) within the range where eBay would have kept the MBI the same throughout the auction. For the the 15 euro cards, the reservation price was 8 euro (about $\$ 12$ ) in the experiment and the maximum value of the object for the buyers was 15 euro (about $\$ 22.5)$. Therefore, the current price was always between $\$ 5$ and $\$ 24.99$, also allowing for reasonable changes in the currency exchange rates between the euro and the US dollar. In practice, the 1 cent MBI cards have a 7.99 euro starting price level, 33 cent MBI cards have 7.67 euro and 50 cent MBI cards have 7.5 euro. Since the first accepted bid is the starting price level plus the MBI, all the cards have a de facto reservation price of 8 euro. In the 50 euro card experiment, I followed the same logic and set the de facto reservation price to 30 euro. The MBI level for the 15 euro cards would have been $\$ 0.50$ (about 33 cents around the experiment date) and $\$ 1$ (about 66 cents) for the 50 euro cards in these price ranges.

I sell all the cards in separate auctions that each last 5 days, from Tuesday afternoon to Sunday afternoon. 12 cards are auctioned at the same time. Both the experiments lasts six weeks and constitute each of six 12 card batches (clusters) with each batch including 4 cards of each of the different MBI's. Note that this set up allows for balanced variation in the treatment within each cluster. Therefore, even if the auctions within each cluster are not independent, for example due to the presence of decreasing average transaction costs 
per card bought, the experiment achieves good power with relatively few observations when compared to randomization at only the cluster level. Typical issues that prevent experiments with within cluster variation include risks of contamination, and ethical, political, administrative or financial reasons (Moerbeek 2005). None of these problems are present in my experiment. Moreover, my reputation as seller increased during the experiment, but with within cluster variation in treatment this causes no problems, since this potential effect is easily controlled by adding weekly (cluster) fixed effects to the regressions. These fixed effects also control for any other unobserved weekly changes. Moreover, given that I have within cluster variation and cluster fixed effects in a cross sectional data, I do need to use cluster corrected standard errors (Wooldridge 2006).

\section{Results}

The main questions of interest in this Section are the effects of MBI on the selling price and the number of actual bidders. I observe the selling price and bidding history in the data. The bidding history includes the current price and the current highest bidder after each accepted new bid. Therefore, it does not reveal the bids submitted to the proxy bidding system. Nor does it reveal the true number of actual bidders, since a new bidder may place an accepted bid, but I would only observe that particular bidder if her bid was the highest. Thus, the variable for the number of observed bidder identities, which I call the number of bidders, is a lower bound or a downwards biased proxy for the number of actual bidders. Another proxy for the number of actual bidders is the number of observed bids. One bidder can be observed bidding many times either because they submit many bids (incremental bidding) or because they are the highest bidder while new entrants submit new second highest bids. Thus the number of bids variable is an upper bound or an upwards biased proxy for the number of actual bidders. I analyze both of these proxies. If the effect of MBI on both of these variables is to the same directions, we can be fairly confident that the effect on actual bidders is also to the same direction. I also observe how many times the object is viewed but this is a very noisy signal of the number of potential bidders, since this variable counts all the views of each bidder and the seller. In order not to allow the monitoring of the experiment to influence its results, I viewed each auction within a branch the same number of times. I analyze only selling price, the number of bidder identities and the number of bids.

In table 2, I describe the variables of interest in the first experiment. The mean price is 13.24 euros. The average price is lowest for the 1 cent MBI and highest for the 33 cent MBI but differences are not statistically significant. All the auctions receive bids from at least two different bidders. Both the average number of 
bids and bidders are lower, the higher the MBI is. There is enough variation in all the response variables to warrant meaningful regression analysis.

Table 2. Descriptive statistics for the 15 euro experiment.

\begin{tabular}{|lcccccc|}
\hline Sample & Variable & Obs & Mean & Std. Dev. & Min & Max \\
\hline AlI & price & 72 & 13.24 & 0.20 & 13 & 13.65 \\
$\mathrm{MBI}=1$ & price & 24 & 13.18 & 0.20 & 13 & 13.51 \\
$\mathrm{MBI}=33$ & price & 24 & 13.27 & 0.18 & 13 & 13.65 \\
$\mathrm{MBI}=50$ & price & 24 & 13.26 & 0.22 & 13 & 13.52 \\
$\mathrm{All}$ & bidders & 72 & 3.06 & 0.98 & 2 & 5 \\
$\mathrm{MBI}=1$ & bidders & 24 & 3.25 & 0.99 & 2 & 5 \\
$\mathrm{MBI}=33$ & bidders & 24 & 3.04 & 1.08 & 2 & 5 \\
$\mathrm{MBI}=50$ & bidders & 24 & 2.88 & 0.85 & 2 & 5 \\
$\mathrm{All}$ & bids & 72 & 4.25 & 2.03 & 2 & 10 \\
$\mathrm{MBI}=1$ & bids & 24 & 5.38 & 2.36 & 2 & 10 \\
$\mathrm{MBI}=33$ & bids & 24 & 3.83 & 1.88 & 2 & 8 \\
$\mathrm{MBI}=50$ & bids & 24 & 3.54 & 1.28 & 2 & 6 \\
\hline
\end{tabular}

"price" denotes the winning bid for which the object is also sold. "bidders" means the number of different bidder identities that are observed to submit bids. "bids" is the number of different bids that are observed.

In table 3, I describe the variables of interest in the second experiment. The mean price is 44.46 euros. Conditional descriptive statistics look exactly as in the first experiment. The average price is lowest for the 1 cent MBI and highest for the 66 cent MBI but these differences are smaller than respective standard deviations. All the auctions receive bids from at least two different bidders and both the average number of bids and bidders are lower, the higher the MBI is. Again there is much variation in all the variables. 
Table 3. Descriptive statistics for the 50 euro experiment.

\begin{tabular}{|lcccccc|}
\hline Sample & Variable & Obs & Mean & Std. Dev. & Min & Max \\
\hline AlI & price & 72 & 44.46 & 1.30 & 41 & 46.64 \\
$\mathrm{MBI}=1$ & price & 24 & 44.31 & 1.33 & 41 & 46 \\
$\mathrm{MBI}=66$ & price & 24 & 44.69 & 1.36 & 41 & 46.64 \\
$\mathrm{MBI}=100$ & price & 24 & 44.40 & 1.23 & 41 & 45.4 \\
$\mathrm{All}$ & bidders & 72 & 4.08 & 0.99 & 2 & 7 \\
$\mathrm{MBI}=1$ & bidders & 24 & 4.46 & 0.98 & 3 & 7 \\
$\mathrm{MBI}=66$ & bidders & 24 & 3.92 & 1.10 & 2 & 6 \\
$\mathrm{MBI}=100$ & bidders & 24 & 3.88 & 0.80 & 2 & 5 \\
$\mathrm{All}$ & bids & 72 & 6.25 & 3.16 & 2 & 16 \\
$\mathrm{MBI}=1$ & bids & 24 & 7.50 & 3.12 & 3 & 13 \\
$\mathrm{MBI}=66$ & bids & 24 & 6.29 & 3.69 & 2 & 16 \\
$\mathrm{MBI}=100$ & bids & 24 & 4.96 & 2.01 & 2 & 11 \\
\hline
\end{tabular}

"price" denotes the winning bid for which the object is also sold. "bidders" means the number of different bidder identities that are observed to submit bids. "bids" is the number of different bids that are observed.

The sold objects are identical in all but two dimensions. Since I randomize the order in which the cards are placed on the auction within each patch, only the week that they are put to auction and the MBI differ systematically. Therefore, I regress the variables of interest on week dummies and the treatment dummies. The results are presented in Table 5. Auctions with 1 cent MBI receive more bids and bidders than auctions with higher MBI. Both the eBay levels and the highest MBI brings more revenue to the seller than the 1 cent MBI and the difference is statistically significant at $5 \%$ level in the 15 euro experiment. There is no statistically significant difference between the two treatments but the eBay level brought in a little more money than the highest MBI. These results imply that the eBay level is close to optimal for these auctions, since we would expect that the entry effect would start dominating if MBI was increased further.

In the 15 euro experiment, when the eBay level is compared to the 1 cent MBI, it increased the revenue on average by $0,60 \%$ relative to the nominal level. In the 50 euro experiment, this revenue gain was $0,78 \%$. Relative to the difference between the nominal price and the average selling price, which is an upper bound of the potential buyer's gains and an exact value for the average cost of this experiment per observational unit, the revenue gain for setting the eBay level was considerable. Setting the eBay level instead of the 1 cent level would have reduced the unit costs of this experiment by $5,1 \%$ on average. For the 50 euro experiment, this measure of the revenue gain is $6,9 \%$. 
To run the pooled regressions on price, I construct a new variable called "discount". It is calculated by dividing the selling price with the nominal value of the card. It is very interesting to note from Table 4 , that this discount is very much the same in both the experiments. One interpretation of this result is that transaction costs are not very important, since a fixed transaction cost should make the average of my discount variable larger for the low value than for the high value cards. It also makes sense now to run a pooled regression, since especially the mean and to less extent the variance of the explanatory variable are about the same in both the experiments.

Table 4. Discount comparisons.

\begin{tabular}{|llccccc|}
\hline Experiment & Variable & Obs & Mean & Std. Dev. & Min & Max \\
\hline Value 15 & discount & 72 & 0.88 & 0.013 & 0.87 & 0.91 \\
Value 50 & discount & 72 & 0.89 & 0.026 & 0.82 & 0.93 \\
\hline
\end{tabular}

According to the pooled results in Table 5, using the eBay increments increase the seller revenue compared to using the 1 cent MBI on average by $0.68 \%$ of the nominal value or by $0.77 \%$ of the average selling price.. This result is statistically significant at $5 \%$ level. Although the percentage of the revenue increase is small compared to the nominal value of the object for sale, it is again a quite large share of the costs of the experiment, namely 5,7\%. Moreover, if you aggregate over all the transactions conducted for example in the eBay, even this small percentage of $0.77 \%$ would have amounted to 460 million dollars of difference in total trades in 2007. 
Table 5. OLS estimation results of the two experiments separately and using the pooled data.

\begin{tabular}{|c|c|c|c|c|c|c|c|c|c|}
\hline & Coef. & Std. Err. & p-value & Coef. & Std. Err. & p-value & Coef. & Std. Err. & p-value \\
\hline Experiment 1 & \multicolumn{3}{|c|}{ price } & \multicolumn{3}{|c|}{ bidders } & \multicolumn{3}{|c|}{ bids } \\
\hline mbi33 & 0.090 & 0.043 & 0.040 & -0.21 & 0.20 & 0.301 & -1.54 & 0.43 & 0.001 \\
\hline mbi50 & 0.081 & 0.043 & 0.064 & -0.38 & 0.20 & 0.065 & -1.83 & 0.43 & 0.000 \\
\hline Constant & 13.107 & 0.050 & 0.000 & 3.28 & 0.23 & 0.000 & 5.96 & 0.49 & 0.000 \\
\hline Week FE & \multirow{2}{*}{\multicolumn{3}{|c|}{$\begin{array}{c}\text { yes } \\
72\end{array}$}} & \multicolumn{3}{|c|}{ yes } & \multicolumn{3}{|c|}{ yes } \\
\hline $\mathrm{N}$ & & & & & 72 & & & 72 & \\
\hline R squared & \multicolumn{3}{|c|}{0.49} & \multicolumn{3}{|c|}{0.55} & \multicolumn{3}{|c|}{0.52} \\
\hline Experiment 2 & \multicolumn{3}{|c|}{ price } & \multicolumn{3}{|c|}{ bidders } & \multicolumn{3}{|c|}{ bids } \\
\hline mbi66 & 0.380 & 0.249 & 0.132 & -0.54 & 0.20 & 0.009 & -1.21 & 0.51 & 0.022 \\
\hline mbi100 & 0.092 & 0.249 & 0.713 & -0.58 & 0.20 & 0.005 & -2.54 & 0.51 & 0.000 \\
\hline Constant & 44.872 & 0.287 & 0.000 & 4.63 & 0.23 & 0.000 & 8.67 & 0.59 & 0.000 \\
\hline Week FE & \multirow{2}{*}{\multicolumn{3}{|c|}{$\begin{array}{l}\text { yes } \\
72\end{array}$}} & \multicolumn{3}{|c|}{ yes } & \multicolumn{3}{|c|}{ yes } \\
\hline$N$ & & & & & 72 & & & 72 & \\
\hline R squared & \multicolumn{3}{|c|}{0.61} & \multicolumn{3}{|c|}{0.55} & \multicolumn{3}{|c|}{0.71} \\
\hline Pooled & \multicolumn{3}{|c|}{ discount } & \multicolumn{3}{|c|}{ bidders } & \multicolumn{3}{|c|}{ bids } \\
\hline Treatment 1 & 0.0068 & 0.0029 & 0.019 & -0.38 & 0.14 & 0.009 & -1.38 & 0.33 & 0.000 \\
\hline Treatment 2 & 0.0036 & 0.0029 & 0.207 & -0.48 & 0.14 & 0.001 & -2.19 & 0.33 & 0.000 \\
\hline Constant & 0.8741 & 0.0044 & 0.000 & 3.37 & 0.22 & 0.000 & 6.02 & 0.51 & 0.000 \\
\hline Week FE & \multicolumn{3}{|c|}{ yes } & \multicolumn{3}{|c|}{ yes } & \multicolumn{3}{|c|}{ yes } \\
\hline$N$ & \multirow{2}{*}{\multicolumn{3}{|c|}{144}} & \multirow{2}{*}{\multicolumn{3}{|c|}{$\begin{array}{c}144 \\
0.64\end{array}$}} & \multirow{2}{*}{\multicolumn{3}{|c|}{$\begin{array}{c}144 \\
0.64\end{array}$}} \\
\hline R squared & & & & & & & & & \\
\hline
\end{tabular}

All the regressions include dummies for different weekly experiment batches. The reference group for these week fixed effects is always the first experiment week of the given sample. The reference (control) group for the treatment effects in all the regressions is the 1 cent MBI. "mbi33" and "mbi50" denote dummies for the 33 cent and 50 cent MBI treatments in the first experiment. In the price regression, the null hypothesis for mbi33=mbi50 is not rejected (p-value 0.83 ). In the number of participating bidders regression, the null hypothesis for mbi33=mbi50 is not rejected (p-value 0.41). In the number of submitted bids regression, the null hypothesis for mbi33=mbi50 is not rejected (p-value 0.50). "mbi66" and "mbi100" denote dummies for the 66 cent and 100 cent MBI treatments in the second experiment. For the effects of MBI on the price, the null hypothesis for mbi66=mbi100 is not rejected (p-value 0.25). In the number of participating bidders regression, the null hypothesis for mbi66=mbi100 is not rejected (p-value 0.83). In the number of submitted bids regression, the null hypothesis for mbi66=mbi100 is rejected (p-value 0.01). "Treatment 1" includes both the 33 cent and 66 cent MBI's. Treatment 2 includes both the 50 cent and the 100 cent MBI's. For the effects of MBI on the discount, the null hypothesis for Treatment $1=$ Treatment 2 is not rejected (p-value 0.27 ). In the number of participating bidders regression, the null hypothesis for Treatment $1=$ Treatment 2 is not rejected (p-value 0.46). In the number of submitted bids regression, the null hypothesis for Treatment $1=$ 
Treatment 2 is rejected (p-value 0.02$)$.

In Table 6, I present the results for running the regressions while treating MBI as a continuous variable instead of a treatment dummy. I also include a quadratic term of MBI. This allows for calculation of the optimal value of the MBI for both the experiments. Although the standard errors for the effect of MBI on prices are quite large here, this provides a best guess for the optimal values. For the 15 euro cards it would have been 38 cents and for the 50 euro cards it would have been 54 cents. eBay level is very close to this.

Table 6. Results for calculating the optimal value of MBI.

\begin{tabular}{|l|ccc|ccc|}
\hline \multirow{2}{*}{ Variable } & \multicolumn{3}{|c|}{ Value 15 } & \multicolumn{3}{c|}{ Value 50 } \\
\cline { 2 - 7 } w2 / w8 & Coef. & Std. Err. & p-value & Coef. & Std. Err. & p-value \\
w3 / w9 & -0.155 & 0.061 & 0.01 & -1.577 & 0.352 & 0.000 \\
w4 / w10 & 0.065 & 0.061 & 0.29 & -2.247 & 0.352 & 0.000 \\
w5 / w11 & 0.140 & 0.061 & 0.03 & 0.219 & 0.352 & 0.536 \\
w6/ w12 & 0.285 & 0.061 & 0.00 & 0.450 & 0.352 & 0.206 \\
mbi & 0.103 & 0.061 & 0.10 & -0.243 & 0.352 & 0.492 \\
mbisq & 0.516 & 0.352 & 0.15 & 1.553 & 0.988 & 0.121 \\
Constant & -0.687 & 0.698 & 0.33 & -1.446 & 0.991 & 0.150 \\
\hline optimal mbi & 13.102 & 0.051 & 0.00 & 44.856 & 0.290 & 0.000 \\
\hline
\end{tabular}

\subsection{External validity}

Being a randomized trial with identical objects, the internal validity of these results is very strong. However, the external validity may be less strong for three reasons. The results may not generalize with respect to the characteristics of the bidders, the sold objects and the auction site.

The first reason is related to whether the bidders represent a typical set of bidders in Internet auctions. In table 7, I describe how many auctions each of the observed bidders won. Altogether 13 different bidder identities are observed in the data. 8 different identities won auctions in the first experiment and 8 in the second, of which 3 were winners also in the first experiment. A large share of the auctions are won by bidder 1. She dominates especially the first experiment, which may be a concern for the external validity of these results. Besides winning most objects, this bidder pays on average the lowest prices. The issue in the first experiment is that, although there are many different bidders that participate in these auctions, one bidder 
wins most of the auctions. It is tempting to argue that the results could have been different if that particular bidder was not present. On the other hand, this particular bidder does not dominate the second experiment and yet the results are very similar in both the first and the second experiment. Moreover, the results from the pooled regression that excludes bidder 1 are qualitatively similar to full sample results (see Appendix). Moreover, the price is not determined by the winning bidder alone, as in the standard first price auctions, but rather as a joint function of both the highest and the second highest bid, as can be seen from equation (1). In these experiments, there is much more variation in the sets of participants than there is in the winner identities. For these reasons, the external validity of these results with respect to bidders should be fairly strong.

Table 7. How many auctions each bidder won?

\begin{tabular}{|c|c|c|c|c|c|c|c|c|c|c|c|c|c|c|}
\hline bidder & w1 & w2 & w3 & w4 & w5 & w6 & w7 & w8 & w9 & w10 w11 & w12 & total & bid 15 & bid $\mathbf{5 0}$ \\
\hline 1 & 11 & 12 & 6 & 12 & 5 & 9 & 4 & 11 & 8 & & & 78 & 13.16 & 43.1 \\
\hline 2 & 1 & & & & & & & & & & 1 & 2 & 13.35 & 45 \\
\hline 3 & & & 4 & & & & & & & & & 4 & 13.45 & NA \\
\hline 4 & & & 1 & & & 1 & & & & & & 2 & 13.49 & NA \\
\hline 5 & & & 1 & & & & & & & & & 1 & 13.5 & NA \\
\hline 6 & & & & & 5 & & & & 4 & & & 9 & 13.51 & 45.02 \\
\hline 7 & & & & & 2 & & & & & & & 2 & 13.5 & NA \\
\hline 8 & & & & & & 2 & & & & & & 2 & 13.42 & NA \\
\hline 9 & & & & & & & 7 & & & & & 7 & NA & 45.13 \\
\hline 10 & & & & & & & 1 & 1 & & & & 2 & NA & 43.52 \\
\hline 11 & & & & & & & & & & 8 & 9 & 17 & NA & 44.87 \\
\hline 12 & & & & & & & & & & 4 & & 4 & NA & 45.72 \\
\hline 13 & & & & & & & & & & 12 & 2 & 14 & NA & 45.39 \\
\hline
\end{tabular}

"w1-6" denote the weeks from 1 to 6 that consist the first experiment. "w7-12" are the weeks of the second experiment. "bid 15" denotes the average winning bid of each bidder in the first experiment and "bid 50" in the second experiment.

The second potential concern for the external validity of the results is related to whether the sold objects represent well a typical object sold in the Internet auctions. Although there were many other types of gift cards for sale at the same time, only few other Stockmann gift cards were present. Thus the object that I sell is not a typical object. Moreover, there is large heterogeneity of objects sold in Internet auctions. Because most imaginable object are sold there, such a thing as representative object of sale does not exist. Thus it is more relevant to concentrate on selling objects that guarantee the internal validity of the results. Therefore, 
large demand and small characteristics space of the sold objects is more important than how common the object is. Furthermore, it is not clear why the results should be related to object characteristics as such. The effect of MBI depends more on the bidder characteristics and their strategies, and their risk attitudes and the nature of entry process. To the extend that these factors vary systematically between different products, the external validity is questionable. Even if some peculiar product or market characteristic would make all the bidders use incremental bidding in one market, truthful proxy bidding in some other other marker and strategic bidding in yet another market, there should be a huge number of markets where the entry behavior and bidder characteristics are similar enough to the Stockmann gift card markets that these results are of external interest. For these reason, the external validity of these results also with respect to the sold objects should be fairly strong.

The main concern for external validity is caused by the differences between Huuto.net and the other Internet auctions sites, most importantly eBay. One difference between the auction mechanisms used by Huuto.net and eBay, is that the former applies a soft stopping rule and the latter a strict stopping rule. The soft closing rule in Huuto.net means that if a bid is submitted when the auction is about to close in less than 5 minutes, 5 minutes are added to the time that auction is open. In eBay the closing time is strict. Also for example the Amazon auctions use a soft closing rule. Stopping rule has implications on the equilibrium bidding. In particular, the strategic advantages of the so called late bidding or sniping, that is often observed in eBay, are severely attenuated in auctions that apply an automatic extension rule (Ockenfels and Roth 2006). In Yahoo! auctions, the seller can set the closing rule. Brown and Morgan (2009) use this feature to construct a field experiment on the effects of the closing rule. They find that prices and bidder counts are unaffected by the auction ending rule. Therefore, it is fair to assume that the results obtained from a field experiment set up in Huuto.net apply also to eBay and other platforms that use the strict closing rule.

There are two other differences between the auction two sites that are more problematic. First, Huuto.net imposes preferential treatment to winners who have placed their bid to the proxy earlier than the second highest bid is placed. In that case, the winner pays only the second highest bid. Therefore, in the case of early placed winning bids, Huuto.net auctions are really just second price auctions instead of hybrid auctions that use the pricing rule (1). In my experiments, $28 \%$ of auctions were won by early proxy bidder. This set up creates further incentives for early bidding beyond the soft closing rule. In my experiment, no late bidding was observed. Due to this rule, I am probably estimating the lower bound for the effects of MBI compared to conducting this experiment in eBay, because equation (1) is only active in auctions where the late proxy bidder wins. Therefore, qualitatively my findings should be robust for this difference in pricing rule. Second, bidders are allowed to jump bid. If jump bidder wins, she pays her bid. Unlike in eBay, bidders are not forced to use the proxy machine but it is rather just an option. $23 \%$ of the auctions in my 
experiments were won by a jump bid. This is a nonnegligible share. Unfortunately, jump bidding creates many complexities to the analysis of bidding strategies that are clearly beyond the scope of this paper. In this respect, external validity is limited. However, a win by jump bidding was equally common in all the three different MBI treatment groups, which may imply that results concerning MBI should not be much affected by the possibility of jump bidding. Moreover, I repeat the analysis by excluding observations that result in jump bid winning (see Appendix). The effects on revenue are slightly larger and the effect on entry smaller for this sample than the full sample. Therefore, it seems that on average jump bidders may be able to deter entry more succesfully with high MBI and thus generate some rents that partly counter the effect of MBI price. Moreover, this subsample analysis again suggests that I may be estimating a lower bound of the revenue effect in comparison to the eBay mechanism. I account for these different rules and strategies also in the structural test by analysing a subsample of data.

\section{$5 \quad$ Testing theory}

I found in my experiments that the optimal MBI is larger than zero. I discussed previously that the main candidates that could explain the revenue gains from higher than zero MBI are risk aversion, budget constraints and truthful bidding. In this section, I test for truthful bidding using the data generated by my experiments. The tests cannot distinguish between the different strategic explanations but they can potentially reject truthful bidding. If that is the case, we can conclude that the second price auction framework is not the proper model for the analysis of Internet auctions.

The test hypothesis is formulated as

$H_{0}$ : Truthful bidding

$H_{1}$ : Strategic bidding that accounts for MBI

First, I use the bid history data to infer which auctions used which of the four the possible price rules. In Table 8, I show these pricing rules, how a given pricing rule is identified and the how the valuations are calculated under under each pricing rule assuming $H_{0}$. I denote the winning or selling price with $W P$, highest bid with $H B$ and second highest bid with $S H B . t_{H B}$ and $t_{S H B}$ denote the time that these bids are submitted. $V$ denotes valuation and $N: N$ is the highest order statistic among $N$ realizations of a random variable and $(N-1): N$ is the second highest order statistic. 


\section{Table 8. Pricing rules and value function estimation}

$\begin{array}{lllll}\text { Pricing rule } & \text { Timing } & \text { Bid history } & \text { Valuation calculus } & \text { Share } \\ W P=S H B+M B I \text { (eq. (1)) } & t_{H B}>t_{S H B} & W P-S H B=M B I & W P-M B I=V_{(N-1): N} & 48 \% \\ W P=H B \text { (eq. (1)) } & t_{H B}>t_{S H B} & W P-S H B<M B I & W P=V_{N: N} & 2 \% \\ W P=H B \text { (jump bid) } & \text { not relevant } & W P-S H B>M B I & \text { Not conducted } & 23 \% \\ W P=S H B \text { (early winner) } & t_{H B}<t_{S H B} & W P-S H B=0 & W P=V_{(N-1): N} & 28 \%\end{array}$

It is possible to detect all the different pricing rules that are used based on the bid history. Second price rule with MBI was used if the last observed price increase is exactly MBI. First price rule was used if the last price increase is smaller than the MBI. In Hickman's (2010) eBay data, about $22 \%$ of the auctions used first price rule. In my data, only $2 \%$ of all the auctions and $5 \%$ of the auctions that ended with the pricing rule determined by the equation (1) use this pricing rule. Compared to Hickmann's (2010) data, this is a low number even when accounting for the fact that in third of my auctions (those with 1 cent MBI), the first price rule is not possible. Moreover, $2 \%$ is a very low number compared to the emphasize I put on the pricing equation (1). However, its rare presence in my data set does not mean that MBI is not accounted for in the bidding strategies. The last price increase can be larger than MBI only if jump bid wins the auction. And the last price increase can be zero only if an early proxy bidder wins the auction. Due to the use of this preferential treatment of early bidders, it is harder to reject the null hypothesis than it would be if the same experiment was ran without this preferential treatment.

I estimate the value functions for both the experiments separately under different MBI's by utilizing order statistics as in Table 8. Only the winning price data can be used. This estimation strategy assumes $H_{0}$. Auctions with jump bid winner are omitted because it is not realistic to assume $H_{0}$ for them. The number of potential bidders $N$ is unknown, but it can be assumed to be the same within each batch or within each experiment and it can be estimated. I use the total number of bidder identities observed in all the auctions in the entire experiment. This is 8 for all the observations in my data. Given balanced batches with respect to different MBI levels, the assumption on $N$ should not influence the results to large extent. Given $N$ and the pricing rule, I can use order statistic formulas and estimate the distribution of the valuation $F(V)$ either with nonparametric or parametric techniques. I use parametric approach due to the small number of observation. Experimental data is very useful in this exercise because there are no observable or unobservable characteristics that should be controlled for. I divide the calculated valuations by the nominal value $N P=15$ or 50 , and then estimate the parameters of a Weibull distribution that is upper truncated at 1 . The test hypothesis for the two experiments is

$$
H_{0}: F(V \mid M B I=1, N P=15)=F(V \mid M B I=33, N P=15)=F(V \mid M B I=50, N P=15)
$$


$H_{1}: F(V \mid M B I=1, N P=15) \neq F(V \mid M B I=33, N P=15)$ or $F(V \mid M B I=1, N P=15) \neq$ $F(V \mid M B I=50, N P=15)$ or $F(V \mid M B I=33, N P=15) \neq F(V \mid M B I=50, N P=15)$, and

$$
\begin{gathered}
H_{0}: F(V \mid M B I=1, N P=50)=F(V \mid M B I=66, N P=50)=F(V \mid M B I=100, N P=50) \\
H_{1}: F(V \mid M B I=1, N P=50) \neq F(V \mid M B I=66, N P=50) \text { or } F(V \mid M B I=1, N P=50) \neq \\
F(V \mid M B I=100, N P=50) \text { or } F(V \mid M B I=66, N P=50) \neq F(V \mid M B I=100, N P=50) .
\end{gathered}
$$

In Table 9, I present the results of testing. I test both for the differences in the empirical cumulative distributions (Figure 2) and differences between the estimated parameters of the Weibull distributions (Figures 3 and 4). I reject the $H_{0}$ of truthful bidding. Therefore, the bidders seem to shade their bids strategically. Reacting to strategically to risk aversion or budget constraints are possible candidate explanations but not the only possible ones. Overall, this Section implies that most of the previous literature that assumes that Internet auctions are second price auctions are overly simplistic.

Figure 2. Empirical cumulative distributions for the valuations calculated under H0.
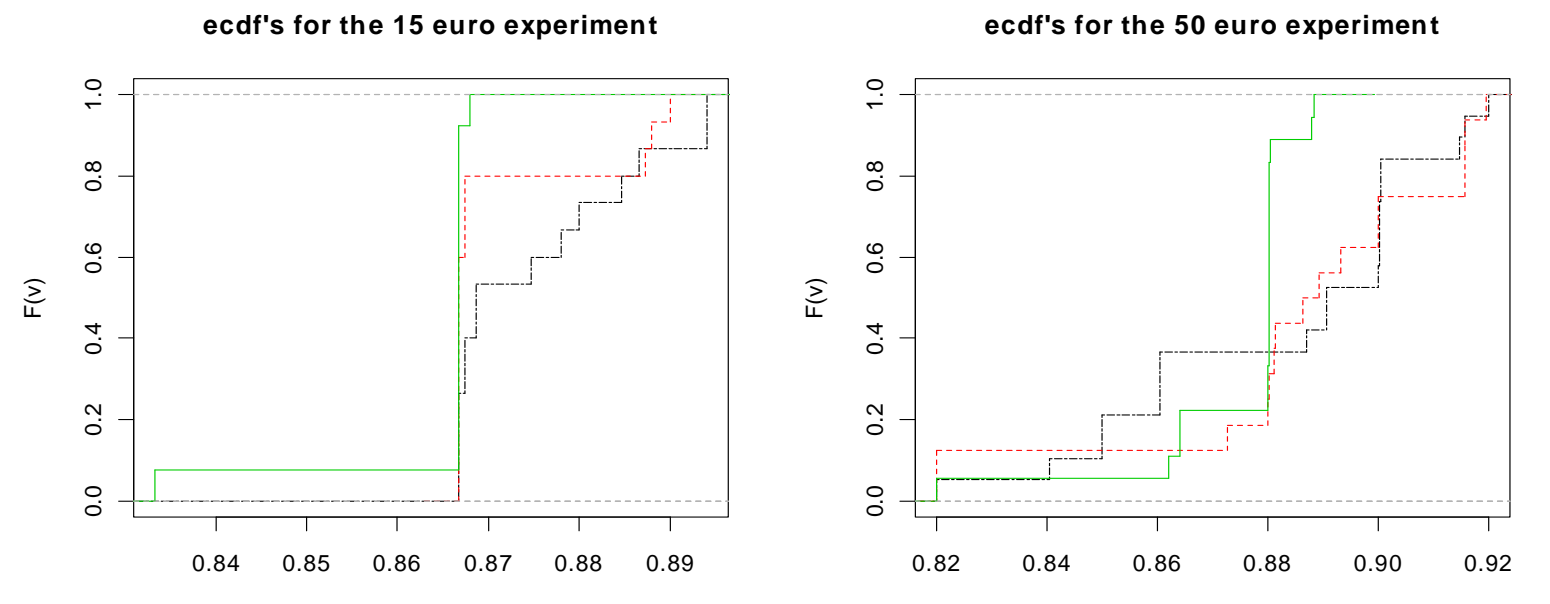

The valuation under truthful bidding divided by the nominal value

The valuation under truthful bidding divided by the nominal value

The green connected line represent the high MBI auction, the red dotted line the mid range MBI auctions and the black semi-dotted line the low MBI auction. 
Figure 3. Estimated cumulative Weibull distributions for the valuations calculated under Ho.

Estimated cum. valuation dist., 15 euro experiment

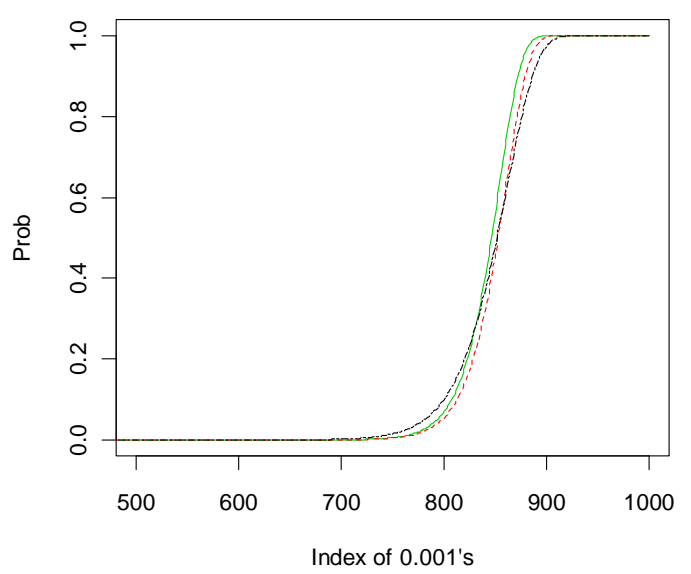

Estimated cum. valuation dist., 50 euro experiment

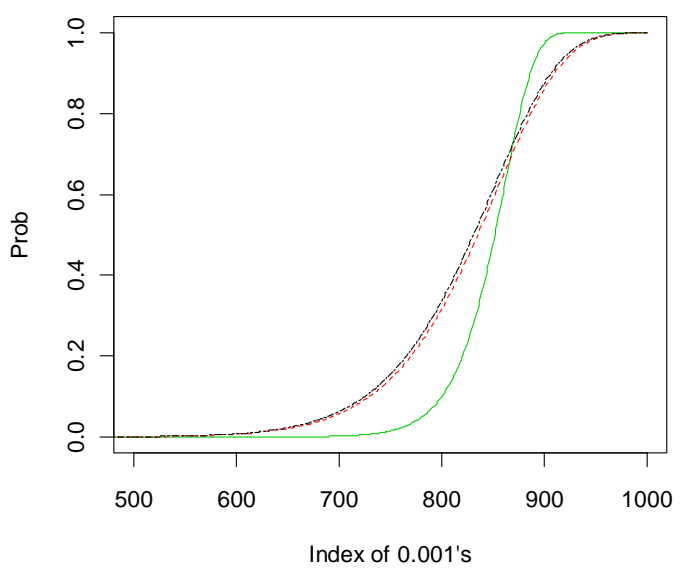

The green connected line represent the high MBI auction, the red dotted line the mid range MBI auctions and the black semi-dotted line the low MBI auction.

Figure 4. Estimated Weibull density distributions for the valuations calculated under H0.

Estimated valuation densities, 15 euro experiment

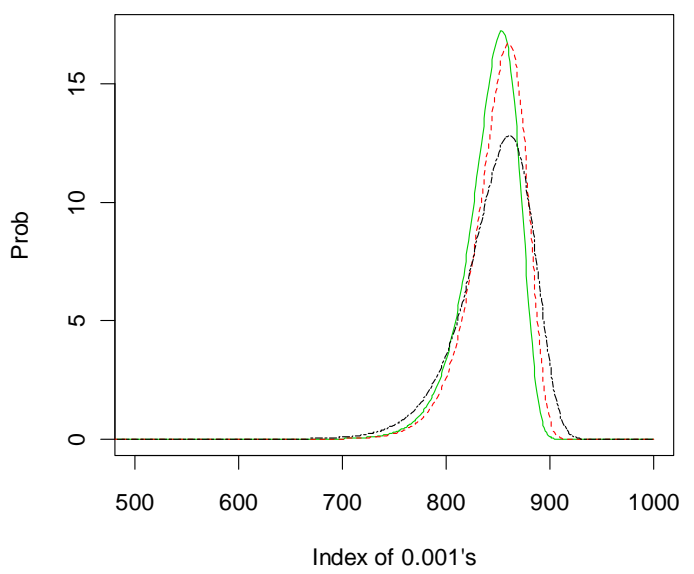

Estimated valuation densities, 50 euro experiment

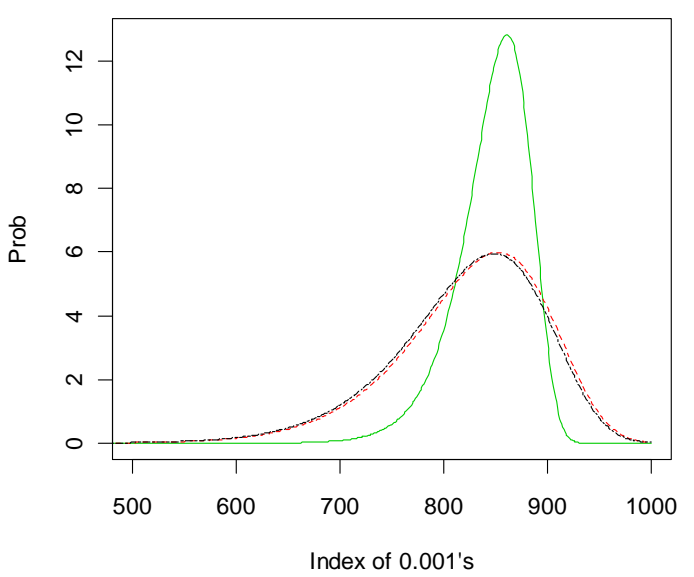

The green connected line represent the high MBI auction, the red dotted line the mid range MBI auctions and the black semi-dotted line the low MBI auction. 
Table 9. Testing for truthful bidding.

\begin{tabular}{|c|c|c|c|c|c|c|}
\hline \multirow[b]{3}{*}{ MBI } & \multicolumn{3}{|c|}{15 euro experiment } & \multicolumn{3}{|c|}{50 euro experiment } \\
\hline & \multicolumn{6}{|c|}{ Location and shape parameters of the Weibull distribution } \\
\hline & 1 & 33 & 50 & 1 & 66 & 100 \\
\hline Location & $0.862 * * *$ & $0.861 * * *$ & $0.854 * * *$ & $0.85 * * *$ & $0.86 * * *$ & $0.86 * * *$ \\
\hline se & 0.0042 & 0.0032 & 0.0038 & 0.0084 & 0.0092 & 0.0042 \\
\hline Shape & $30.0 * * *$ & $39.1 * * *$ & $40.0 * * *$ & $13.8 * * *$ & $13.9 * * *$ & $30.0 * * *$ \\
\hline \multirow[t]{2}{*}{ se } & 5.70 & 9.94 & 9.67 & 2.35 & 2.66 & 5.70 \\
\hline & \multicolumn{6}{|c|}{ Testing for differences in the Weibull parametes } \\
\hline MBI & $1-33$ & $1-50$ & $33-50$ & $1-66$ & $1-100$ & $66-100$ \\
\hline Location & 0.0013 & 0.0080 & 0.0067 & -0.0087 & -0.0039 & -0.0048 \\
\hline se & 0.0053 & 0.0056 & 0.0049 & 0.0094 & 0.0125 & 0.0101 \\
\hline Shape & -9.08 & -9.97 & -0.90 & -0.16 & $-16.27^{*}$ & $-16.1^{*}$ \\
\hline \multirow[t]{2}{*}{ se } & 8.99 & 11.22 & 11.90 & 3.55 & 6.17 & 6.29 \\
\hline & \multicolumn{6}{|c|}{ Testing for differences in the ecdf's } \\
\hline MBI & $1-33$ & $1-50$ & $33-50$ & $1-66$ & $1-100$ & $66-100$ \\
\hline t-test & & $* *$ & & $* *$ & & \\
\hline Wilcox-test & & $* * *$ & $*$ & & & $*$ \\
\hline KS-test & & $* *$ & & & $* *$ & $* *$ \\
\hline
\end{tabular}




\section{Conclusions}

In this study, I argue that MBI is an important yet previously overlooked feature of Internet auctions. I conduct a field experiment to study the effects of MBI on both entry and seller revenue in Internet auctions. The institutional set up of the Finnish Internet auction site Huuto.net allows for a novel field experiment. I sell otherwise identical objects with different MBI's. To my knowledge, this is the first experimental study on this subject. I find that it is optimal for the seller to set the minimum bid increment level higher than the smallest possible level. The level corresponding to the eBay schedule seems to be a good choice. I also find that the number of actual bidders is decreasing in the MBI. Since my experiment reveals that MBI is a relevant determinant of both of these outcomes, the effects MBI on bidder behavior and auction outcomes should be incorporated into further analyzes of Internet auctions.

I also discuss some potential theoretical explanations for the results of my experiment. This discussion is based mainly on existing literature. The main candidates that can explain the positive effect of nonzero MBI on seller revenue are truthful bidding and strategic reaction to risk aversion or budget constraints. I use a structural econometric test to distinguish between these theoretical explanations. I reject the truthful bidding hypothesis. This implies that these auctions cannot be modeled as second price auctions. This observation challenges the validity of many previous studies on Internet auctions.

In summary, this paper discusses some theory on the role of MBI in Internet auctions, and especially presents a novel field experiment that is both internally and externally fairly valid and provides statistically significant and economically nonnegligible results on the effects of MBI on auction outcomes. Furthermore, I propose and use a test to distinguish between a behavioral and a strategic explanation of the results. This study can also be seen as an evaluation of the eBay bid increment schedule. I find no evidence that the eBay schedule would not be well chosen. However, this study does not allow analyzing whether there should be more steps in the eBay schedule nor do we know if the schedule is well chosen when selling object of different values than analyzed here. 


\section{$7 \quad$ References}

Andrews T, Benzing C (2007). "The Determinants of Price in Internet Auctions of Used Cars". Atlantic Economic Journal 35, 43-57.

Arrowsmith S (2006). "The Past and Future Evolution of EC Procurement Law from Framework to Common Code. Public Contract Law Journal 35, 337-384.

Bajari P, Hortacsu A (2003). "The Winner's Curse, Reserve Prices, and Endogenous Entry: Empirical Insights from eBay Auctions. The RAND Journal of Economics 34, 329-355.

Bajari P, Hortacsu A (2004). "Economic Insights from Internet Auctions" Journal of Economic Literature $42,457-486$.

Bapna R (2003). "When Snipers Become Predators: Can Mechanism Design Save Online Auctions?". Communications of the ACM 46, 152-158.

Bapna R, Goes P, Gupta A (2003). Analysis and Design of Business-to-Consumer Online Auctions. Management Science 49, 85-101.

Brown J, Morgan J (2009). How Much Is a Dollar Worth? Tipping versus Equilibrium Coexistence on Competing Online Auction Sites. Journal of Political Economy 117, 668-700.

Canals-Cerda J (2006). "Advertising as a Signal in an Internet Auctions Market". SSRN Working paper.

Che Y-K, Gale I (1998). "Standard Auctions with Financially Constrained Bidders". Review of Economic Studies 65, 1-21.

Chwe M (1989). "The Discrete Bid First Price Auction". Economic Letters 31, 303-306.

David E, Rogers A, Jennings N, Schiff J, Kraus S, Rothkopf M (2007). "Optimal Design of English Auctions with Discrete Bid Levels". ACM Transactions on Internet Technology Vol. 7, No. 2, Article 12.

Hickman, B (2010). On the Pricing Rule in Electronic Auctions. International Journal of Industrial Organization 28, 423-433.

Hortacsu A, Nielsen E (2010). "Do Bids Equal Values on eBay". Marketing Science 29, 994-997.

Katkar R, Reiley D (2006). Public Versus Secret Reserve Prices in eBay Auctions: Results from a Pokemon Field Experiment. Advances in Economic Analysis and Policy 6, Issue 2, Article 7.

Krishna V (2002). Auction Theory. Academic Press.

Maskin E, Riley J (1984). Optimal Auctions with Risk Averse Buyers. Econometrica 52, 1473-1518.

Milgrom P, Weber R (1982). A Theory of Auctions and Competitive Bidding. Econometrica 50, 10891122.

Moerbeek M (2005). Randomization of Clusters Versus Randomization of Persons Within Clusters: Which Is Preferable? The American Statistician 59, 72-78. 
Myerson R (1981). Optimal Auction Design. Mathematics of Operations Research 6, 58-73.

Ockenfels A, Reiley D, Sadrieh A (2006). "Online Auctions". In Hendershott T(ed),.Handbooks in Information Systems I, Handbook on Economics and Information Systems, 571-628.

Ockenfels A, Roth A (2006). "Late and Multiple Bidding in Second Price Internet Auctions: Theory and Evidence Concerning Different Rules for Ending an Auction". Games and Economic Behavior 55, 297-320.

Reiley D (2006). "Field Experiments on the Effects of Reserve Prices in Auctions: More Magic on the Internet". RAND Journal of Economics 37, 195-211.

Renda A, Schrefler L (2006). "The Public Procurement Directives: Transposition in EU Member States". Briefing Note IP/A/IMCO/OF/2006-071. DG Internal Policies of the Union.

Resnick P, Zeckhauser R, Swanson J, Lockwood K (2006). "The Value of Reputation on eBay: A Controlled Experiment." Experimental Economics 9, 79-101.

Riley J, Samuelsson W (1981). Optimal Auctions. American Economic Review 71, 381-392.

Rogers A, David E, Jennings N, Schiff J (2007). "The Effects of Proxy Bidding and Minimum Bid Increments within eBay Auctions". ACM Transactions on the Web 1, No. 2, Article 9.

Roth A, Ockenfels A (2002). "Last-Minute Bidding and the Rules for Ending Second-Price Auctions: Evidence from eBay and Amazon Auctions on the Internet". The American Economic Review 92, 1093-1103.

Rothkopf M, Harstad R (1994). "On the Role of Discrete Bid Levels in Oral Auctions". European Journal of Operations Research 74, 572-581.

Song U (2004). "Nonparametric Estimation of an eBay Auction Model with Unkown Number of Bidders". Working paper, University of British Columbia.

Standifird S, Roelofs M, Durham Y (2004). "eBay's Buy-It-Now Function and the Impact on Bidder Behavior". International Journal of Electronic Commerce 9, 167-176.

Zeithammer R, Adams C (2010). "The Sealed Bid Abstraction in Online Auctions". Marketing Science 29, 964-987.

Wooldridge J (2006). "Cluster-Sample Methods in Applied Econometrics: An Extended Analysis". Working paper, Michigan State University. 


\section{Appendix}

Table A1. Pooled estimation results for different subsamples of the data.

\begin{tabular}{|c|c|c|c|c|c|c|c|c|c|}
\hline & \multicolumn{3}{|c|}{ discount } & \multicolumn{3}{|c|}{ bidders } & \multicolumn{3}{|c|}{ bids } \\
\hline Sample & \multicolumn{9}{|c|}{ Auctions won by jump bid are excluded } \\
\hline Variable & Coef. & Std. Err. & p-value & Coef. & Std. Err. & p-value & Coef. & Std. Err. & p-value \\
\hline Treatment 1 & 0.0082 & 0.0041 & 0.05 & -0.06 & 0.18 & 0.72 & -1.03 & 0.39 & 0.01 \\
\hline Treatment 2 & 0.0081 & 0.0042 & 0.06 & -0.28 & 0.18 & 0.12 & -2.03 & 0.39 & 0.00 \\
\hline Week FE & & yes & & & yes & & & yes & \\
\hline R squared & & 0.55 & & & 0.61 & & & 0.70 & \\
\hline $\mathbf{N}$ & & 99 & & & 99 & & & 99 & \\
\hline Sample & \multicolumn{9}{|c|}{ Auctions won by bidder 1 are excluded } \\
\hline Variable & Coef. & Std. Err. & p-value & Coef. & Std. Err. & p-value & Coef. & Std. Err. & p-value \\
\hline Treatment 1 & 0.0042 & 0.0025 & 0.10 & -0.88 & 0.20 & 0.00 & -2.14 & 0.59 & 0.00 \\
\hline Treatment 2 & -0.0009 & 0.0024 & 0.71 & -1.10 & 0.19 & 0.00 & -3.79 & 0.56 & 0.00 \\
\hline Week FE & & yes & & & yes & & & yes & \\
\hline R squared & & 0.66 & & & 0.70 & & & 0.74 & \\
\hline $\mathbf{N}$ & & 66 & & & 66 & & & 66 & \\
\hline Sample & \multicolumn{9}{|c|}{ Data lost post revenue estimation but previous to recording the pricing rule info excluded } \\
\hline Variable & Coef. & Std. Err. & p-value & Coef. & Std. Err. & p-value & Coef. & Std. Err. & p-value \\
\hline Treatment 1 & 0.0072 & 0.0032 & 0.02 & -0.41 & 0.15 & 0.01 & -1.52 & 0.36 & 0.00 \\
\hline Treatment 2 & 0.0041 & 0.0032 & 0.20 & -0.52 & 0.15 & 0.00 & -2.43 & 0.36 & 0.00 \\
\hline Week FE & & yes & & & yes & & & yes & \\
\hline R squared & & 0.55 & & & 0.60 & & & 0.69 & \\
\hline $\mathbf{N}$ & & 130 & & & 130 & & & 130 & \\
\hline
\end{tabular}

The lowest sample in Table A1 is needed due to a human error. Originally, I did not record the information from my experiments on the pricing rule that was used. I added that information later. Between these two recording events I lost the back up paper copies of 14 of my auctions while moving office. This lost information is not easily recoverable because Huuto.net keeps the information on their auctions only for 3 months. Therefore, the relevant comparison regression for these two subsamples analyzed here for robustness reasons is not the full sample pooled regression in Table 7, but rather the third regression here. 